\title{
Utmattelse ved inflammatorisk tarmsykdom
}

\begin{abstract}
BAKGRUNN Inflammatorisk tarmsykdom utgjøres i hovedsak av ulcerøs kolitt og Crohns sykdom. Prevalensen av fatigue og assosiasjonen med forskjellige kofaktorer varierer i ulike studier. I denne artikkelen ønsker vi å beskrive omfanget av fatigue ved inflammatorisk tarmsykdom, de vanligste assosierte faktorene og behandling. Vi vil også omtale utfordringer ved fremtidig forskning på fatigue ved inflammatorisk tarmsykdom.
\end{abstract}

KUNNSKAPSGRUNNLAG Vi gjorde litteratursøk i databasene Ovid Medline og The Cochrane Library med kombinasjoner av søkeordene «inflammatory bowel diseases», «inflammatory bowel disease*», «|BD», «crohn*», «colitis», «fatigue», «fatigue manage»

og «fatigue treat». Søket ble begrenset til artikler publisert i perioden 2000-15.

RESULTATER 28 av i alt 156 artikler ble inkludert. 13 ulike instrumenter for å måle fatigue og 11 mål på sykdomsaktivitet ble anvendt i de ulike studiene. Fatigue forekommer hyppigere hos dem som er rammet av inflammatorisk tarmsykdom (22-77\%) enn i normalbefolkningen (2-12\%). Aktiv sykdom og depresjon er assosiert med høyere grad av fatigue.

FORTOLKNING Fatigue er et betydelig problem ved inflammatorisk tarmsykdom, og forekomsten og mulige risikofaktorer varierer fordi det er benyttet ulike mål for grad av utmattelse/fatigue og sykdomsaktivitet i heterogene studiepopulasjoner.

Inflammatorisk tarmsykdom utgjøres i hovedsak av ulcerøs kolitt og Crohns sykdom begge kronisk inflammatoriske tilstander som ofte debuterer i tidlig voksen alder og har et forløp preget av perioder med aktiv sykdom og remisjon. Typiske symptomer er blodig diaré, magesmerter og vekttap (1).

Fatigue rapporteres som en vesentlig helseplage av mange i denne pasientgruppen (2). «Fatigue» kan defineres som en overveldende følelse av tretthet, utmattelse og manglende energi (3). Fenomenet er vanlig ved en rekke kronisk inflammatoriske sykdommer, det påvirker livskvaliteten (4) og reduserer i mange tilfeller arbeidsevnen (5).

Patogenesen bak tilstanden er kun delvis kjent. En ledende hypotese er at den er del av en evolusjonsmessig bevart forsvarsrespons utløst av akutt infeksjon eller inflammasjon (6). Responsen omfatter fatigue, initiativløshet og anoreksi og en passiv, tilbaketrukket atferd - såkalt sykdomsatferd. Hensikten med denne mekanismen er å sikre tilheling og rehabilitering ved sykdom (6).

Immunologiske mekanismer er de mest undersøkte årsaksfaktorene til slik sykdomsatferd. Betennelsesdrivende signalsubstanser (cytokiner) som interleukin-1 $\beta$ og tumornekrosefaktor- $\alpha$ aktiveres ved inflammasjon. Interleukin-1 $\beta$ er blitt knyttet til fatigue både i dyreforsøk og i humane studier (7). Tumornekrosefaktor- $\alpha$ kan også medvirke, ettersom medikamenter som blokkerer denne betennelsesfaktoren ser ut til å gi mindre fatigue ved revmatoid artritt og kanskje også ved inflammatorisk tarmsykdom (8). Utvikling og regulering av fatigue påvirkes også av genetiske og epigenetiske forhold (7).

En rekke andre faktorer, slik som smerte, depresjon og sosiale forhold, kan modifisere eller forsterke opplevelsen av fatigue (7). Depresjon er den sterkeste prediktoren, men tilstanden forekommer også hos pasienter uten andre tilleggsplager (7).

Så langt er fatigue ved revmatiske sykdommer, kreft og ved kronisk utmattelsessyndrom/myalgisk encefalopati mest studert. I de senere år er det imidlertid publisert flere studier om fatigue ved inflammatorisk tarmsykdom. Temaet opptar både pasienter og klinikere. Formålet med denne oversiktsartikkelen er derfor å beskrive forekomsten av fatigue ved inflammatorisk tarmsykdom, sammenfatte foreliggende kunnskap om sammenhengen mellom fatigue, sykdomsaktivitet og andre faktorer og redegjøre for behandling. Vi vil i tillegg omtale metoder for å registrere fatigue og foreslå forbedringspunkter for fremtidig forskning i feltet.

\section{Kunnskapsgrunnlag}

Vi søkte i databasene Ovid Medline og The Cochrane Library med søkeordene «inflammatory bowel diseases», «inflammatory bowel disease*», «IBD», «crohn*», «colitis», «fatigue», «fatigue manage» og «fatigue treat» og kombinasjoner av disse. Søket ble avgrenset til engelskspråklige artikler som omfattet voksne pasienter og var publisert mellom 1.1. 2000 og 12.6. 2015. Oversiktsartikler og rene metodearbeider ble ekskludert. Vi fikk 164 treff etter søk på Ovid medline og 103 treff etter søk på The Cochrane Library. 21 artikler ble funnet i begge databasene, hvorav åtte var relevante. Artiklenes relevans ble vurdert ut fra tittel og sammendrag.

Begge forfatterne leste 35 artikler i fulltekst og gjennomgikk referanselistene. Tre

\section{Tore Grimstad}

tore.bjorn.grimstad@sus.no

Gastroenterologisk seksjon

Stavanger universitetssjukehus

Katrine Brække Norheim

Seksjon for klinisk immunologi

Stavanger universitetssjukehus

Tl Engelsk oversettelse på www.tidsskriftet.no

\section{HOVEDBUDSKAP}

Fatigue forekommer oftere hos pasienter med inflammatorisk tarmsykdom enn hos friske og er et betydelig problem

Aktiv sykdom og depresjon er ofte assosiert med fatigue

Årsakene til og behandlingen av fatigue ved inflammatorisk tarmsykdom er uavklart 
artikler ble inkludert fra eget litteraturarkiv. 21 artikler som omfattet prevalens av fatigue ved inflammatorisk tarmsykdom ble inkludert i tabell 1 (9-29). Tre kvalitative studier og fire rapporter som omhandlet behandling ble også inkludert i denne oversiktsartikkelen - totalt 28 artikler. For kvantitative artikler var utvelgelsen basert på pasientantall $(n \geq 50)$ og at sykdomsaktivitet var registrert.

\section{Måling av fatigue \\ ved inflammatorisk tarmsykdom}

Fatigue er et selvopplevd fenomen, og objektive mål (f.eks. øyeblunking eller skrittlengde) korrelerer dårlig med en subjektiv angivelse (30). Tilstanden bør derfor måles med selvrapportering. Det eksisterer en rekke slike instrumenter, hvorav ett er nylig utviklet og sykdomsspesifikt for inflammatorisk tarmsykdom (31), mens de øvrige er generiske og kan brukes ved flere ulike tilstander.

Instrumentene kan videre deles inn etter antall dimensjoner av tilstanden - unidimensjonale instrumenter registrerer aspekter i én dimensjon, multidimensjonale instrumenter deler fatigue inn i for eksempel fysisk og mental eller kognitiv dimensjon (32).

\section{Forekomst av fatigue}

ved inflammatorisk tarmsykdom

I 21 studier har man undersøkt forekomsten av fatigue ved inflammatorisk tarmsykdom. Studiepopulasjonene varierte betydelig, både i pasientantall (fra 52 (33) til 10634 (16)), inkluderte sykdomsgrupper og om pasientene ble sammenliknet med kontrollpersoner (tab 1) (9-29). I flertallet var pasientene inkludert i en klinisk sammenheng, mens studien med flest deltakere besto av data fra et pasientregister og telefonintervjuer. Samme pasientutvalg var grunnlaget for tre artikler $(21,34,35)$ - derfor er kun en av disse (21) med i oversiktstabellen (tab 1).

I syv av de 21 studiene ble det rapportert data for ulcerøs kolitt og Crohns sykdom separat. Forekomsten av fatigue syntes å være noe høyere ved Crohns sykdom (29-77\%) enn ved ulcerøs kolitt (22-69\%). I samtlige studier der det var inkludert friske kontrollpersoner eller gjort sammenligninger med normalbefolkningen var det økt forekomst av fatigue ved inflammatorisk tarmsykdom (tab 1) (9-29).

\section{Sykdomsaktivitet}

I 18 studier var sammenhengen mellom fatigue og sykdomsaktivitet undersøkt (tab 1), og 13 av disse var tverrsnittsstudier. I 12 av dem var det en (positiv) assosiasjon.

Flertallet inkluderte pasienter med både aktiv og inaktiv sykdom (remisjon), mens tre studier (27-29) kun inkluderte pasienter i remisjon. I én studie var sykdomsaktivitet assosiert med fatigue ved Crohns sykdom, men ikke ved ulcerøs kolitt (10).

\section{Andre faktorer assosiert med fatigue}

Depresjon forekommer oftere hos personer med inflammatorisk tarmsykdom enn i normalbefolkningen (36) og var den hyppigst påviste assosiasjonen til fatigue $\mathrm{i}$ vår samling av artikler. I fire studier $(9,10,13,28)$ hadde man vurdert depresjon $\mathrm{i}$ forhold til fatigue, og i alle var det en signifikant positiv assosiasjon. Andre undersøkte faktorer var tett knyttet opp mot depresjon, slik som sykdomsrelaterte bekymringer, angst, stress og psykososiale forhold $(13,15,19,21,34)$.

Anemi, i hvert fall av alvorlig grad, er en kjent årsak til fatigue ved andre tilstander. I vårt materiale var hemoglobinnivå/anemi assosiert med fatigue i fire av studiene (14, $18,21,24)$, mens det $\mathrm{i}$ åtte $(9,11,15,17,19$, $20,26,27)$ ikke ble påvist noen slik sammenheng.

\section{Livskvalitet og fatigue}

Tre kvalitative studier $(33,37,38)$ med totalt 84 pasienter omhandlet betydningen av fatigue for livskvaliteten. Samtlige konkluderte med at tilstanden innebærer dårligere livskvalitet.

\section{Behandling av fatigue}

Vi fant ingen medikamentstudier der endring i tilstanden var primært endepunkt. I tre studier der man vurderte effekten av TNF-hemmere ved Crohns sykdom var fatigue sekundært endepunkt $(8,39,40)$.

En var enkeltblindet og inkluderte 14 pasienter som fikk placebo i 14 dager, etterfulgt av infliksimab. Placebogruppen fikk et forbigående, signifikant fall i fatiguenivå, mens pasientene som fikk aktivt medikament så ut til å oppnå varig reduksjon (8).

Lichtenstein og medarbeidere fant at signifikant flere som fikk infliksimab $(\mathrm{n}=82)$ enn placebo $(n=23)$ fikk økt energi (39).

I den tredje studien var det et signifikant fall i fatiguenivå hos dem som responderte på fire ukers induksjonsterapi med adalimumab $(n=499)$ og en signifikant forskjell når det gjaldt grad av fatigue etter ett års behandling mellom gruppen som kun fikk induksjonsterapi $(\mathrm{n}=168)$ og gruppen som fikk vedlikeholdsbehandling $(n=324)(40)$.

Psykoterapi har vært anvendt som ikkemedikamentell behandling ved inflammatorisk tarmsykdom og fatigue (41). 98 pasienter med Crohns sykdom i remisjon, men med betydelig grad av fatigue ble inkludert. Forfatterne konkluderer med at psykoterapi har en positiv effekt på grad av fatigue ved inflammatorisk tarmsykdom, men at effekten ser ut til å forsvinne etter avsluttet behandling.

\section{Diskusjon}

Det er økende interesse for fatigue ved inflammatorisk tarmsykdom: I perioden 2000-10 ble det publisert fire studier om temaet, sammenlignet med 17 i perioden 2011-15.

\section{Instrumenter}

Hele 13 ulike instrumenter for å måle fatigue ble identifisert ved denne gjennomgangen. Ett instrument spesifikt for inflammatorisk tarmsykdom er publisert, men erfaringene ved bruk av dette er foreløpig begrenset (31). Noen verktøy registrerer symptomer som kan påvirkes av sykdomsaktivitet eller depresjon. Dermed kan det oppstå en falsk sammenheng, fordi de samme symptomene kan gi økt skår både for fatigue og sykdomsaktivitet. Instrumentene har varierende tidsaspekt for symptomer og grenseverdier, noe som gjør datasammenligning vanskelig. De administreres i tillegg ulikt. Det er ikke sikkert at en pasient vil svare det samme i et telefonintervju som på en skriftlig skala under veiledning av helsepersonell.

Unidmensjonale instrumenter er enkle å bruke i klinisk praksis, men gir begrenset informasjon. Multidimensjonale instrumenter kan gi et bedre totalbilde, men er mer komplisert både å bruke og å tolke, og er mer tidkrevende. Sykdomsspesifikke skjemaer for måling av fatigue er validert for den enkelte tilstand og tar dermed høyde for sykdomsspesifikke faktorer, men resultatene kan ikke sammenlignes på tvers av ulike tilstander.

Det finnes ingen gullstandard for måling av fatigue, men et enkelt generisk instrument som har vært brukt ved flere inflammatoriske sykdommer er Fatigue Visual Ana$\log$ Scale (42). Multidimensional Fatigue Inventory er validert og mer omfattende og ble hyppigst benyttet i vår oversikt (43). Begge skjemaene er oversatt til norsk.

\section{Fatigue og sykdomsaktivitet}

I et flertall av studiene fant man en sammenheng mellom fatigue og grad av sykdomsaktivitet, først og fremst $\mathrm{i}$ skillet mellom aktiv sykdom og remisjon $(10,12,13,15,17-19$, $22,24,26) .40 \%$ av pasienter i remisjon rapporterte fatigue, noe som betyr at flere faktorer enn sykdomsaktivitet er av betydning $(20,24)$.

Flere av målene for sykdomsaktivitet er unøyaktige, og det er dårlig sammenheng mellom symptomskår og endoskopisk grad av inflammasjon (44). Subjektive mål av sykdomsaktivitet (avføringstrang, abdominalsmerter og allmenntilstand) $(45,46)$ vil kunne bidra til at en samtidig funksjonell tarmlidelse (irritabel tarm-syndrom) gjør at sykdomsaktiviteten vil bli overestimert. Samtidig irritabel tarm-syndrom foreligger hos om lag en tredel av pasientene med inflammatorisk tarmsykdom (47).

I kun fire studier $(9,11,14,27)$ var et objek- 
Tabell 1 Prevalens av fatigue ved inflammatorisk tarmsykdom. BFI = Brief Fatigue inventory, D-FIS = Daily fatigue impact scale, FACIT-F = Functional Assessment of Chronic Illness Therapy-Fatigue, FIS = Fatigue Impact Scale, FQ = Fatigue Questionnaire, FSS = Fatigue Severity Scale, fVAS = Fatigue Visual Analog Scale, GSCL = Giessen Subjective Complaints List, PFS = Piper Fatigue Scale, PROMIS = Patient Reported Outcome,

!.A. = ikke angitt

\begin{tabular}{|c|c|c|c|c|c|c|c|c|}
\hline \multirow[b]{2}{*}{$\begin{array}{l}\text { Førsteforfatter } \\
\text { (referanse) }\end{array}$} & \multicolumn{2}{|c|}{ Antall deltagere } & \multirow[t]{2}{*}{ Instrument } & \multicolumn{3}{|c|}{ Prevalens av fatigue [\%] } & \multirow[t]{2}{*}{$\begin{array}{l}\emptyset \text { kt grad av } \\
\text { fatigue sammen- } \\
\text { lignet med friske } \\
\text { kontrollpersoner }\end{array}$} & \multirow[t]{2}{*}{$\begin{array}{l}\text { Fatigue assosiert } \\
\text { med aktiv inflam- } \\
\text { matorisk tarm- } \\
\text { sykdom }\end{array}$} \\
\hline & $\begin{array}{l}\text { Inflamma- } \\
\text { torisk tarm- } \\
\text { sykdom }\end{array}$ & $\begin{array}{c}\text { Friske } \\
\text { kontroll- } \\
\text { personer }\end{array}$ & & $\begin{array}{l}\text { Ulcerøs } \\
\text { kolitt }\end{array}$ & $\begin{array}{l}\text { Crohns } \\
\text { sykdom }\end{array}$ & $\begin{array}{l}\text { Inflam- } \\
\text { matorisk } \\
\text { tarmsyk- } \\
\text { dom }\end{array}$ & & \\
\hline Kappelman (16) & 10634 & & PROMIS & & & & $\mathrm{Ja}$ & Ja \\
\hline Lesage (23) & 930 & 1494 & $\mathrm{MFI}-20$ & & & 50 & & $\mathrm{Nei}$ \\
\hline Romberg-Camps (24) & 707 & & MFI-20 & $69 / 36^{1}$ & $77 / 38^{1}$ & & & Ja \\
\hline Singh (22) & 704 & & Selvrapportert & 33 & 54 & & & $\mathrm{Ja}$ \\
\hline Opheim (12) & 428 & & 5-item FSS & 33 & 43 & & & Ja \\
\hline Bager (17) & 425 & & MFI-20 & & & 44 & & Ja \\
\hline Graff (19) & 318 & & $\mathrm{MFI}$ & & & $72 / 30^{1}$ & & $\mathrm{Ja}$ \\
\hline Graff (15) & 312 & & MFI & & & & & Ja \\
\hline van Langenberg (13) & 294 & 85 & FIS & 47 & 57 & & Ja & Ja \\
\hline Goldenberg (11) & 277 & & MFI & & & 45 & & I.A \\
\hline Cohen (10) & 220 & & FACIT-F & 22 & 30 & & & Ja (CD), nei (UC) \\
\hline Tinsley (18) & 209 & & FACIT-F & & & & & Ja \\
\hline Rømkens (20) & 172 & 50 & PFS & & & 64 & Ja & Nei \\
\hline Jelsness-Jørgensen (21) & 140 & 2287 & $F Q$ & 22 & 29 & & Ja & Nei \\
\hline Yoo (14) & 128 & 92 & FACIT-F, BFI & & & & Ja & Nei \\
\hline Casellas (27) & 115 & & D-FIS & & & & & I.A. \\
\hline Grimstad (9) & 81 & 67 & FSS, fVAS & 42 & 48 & & Ja & Nei \\
\hline Banovic (29) & 81 & & MFI & & & 52 & & Nei \\
\hline Minderhoud (26) & 80 & 67 & MFI & 40 & & & Ja & Ja \\
\hline Häuser (25) & 77 & 1943 & GSCL & & & & Ja & I.A \\
\hline Banovic (28) & 52 & & MFI-20 & & & & & Ja \\
\hline
\end{tabular}

${ }^{1}$ Det er oppgitt separate tall for fatigue i aktiv sykdom/remisjon

tivt mål for inflammasjon (endoskopisk gradering) inkludert. Vår oppfatning er at objektive mål for tarminflammasjon, som nivå av fekal kalprotektin eller endoskopisk gradering, er bedre egnet til å evaluere sykdomsaktivitet.

\section{Fatigue og andre faktorer}

Fysisk fatigue eller tap av energi er et av kriteriene for alvorlig depressiv episode (48). Sammenhengen mellom fatigue og depressive symptomer kan derfor til dels skyldes overlappende symptomatologi.

Den variable sammenhengen mellom anemi og fatigue i vår artikkeloversikt kan skyldes at anemien må være betydelig for å bidra målbart til fatigue ved inflammatorisk tarmsykdom.

Samtidig irritabel tarm-syndrom knyttes til økt grad av fatigue hos pasienter i remisjon (47). Endret søvnmønster kan ha betydning. Søvnvansker kan henge sammen med depresjon eller være sekundært til smerter og diaré nattetid. Redusert søvnkvalitet bidrar til utmattelse og nedsatt energi, men det er viktig å være klar over at fatigue ikke er det samme som søvnighet.
Fremtidige studier av fatigue

Det er behov for studier som beskriver forløpet av fatigue over tid. I en oppfølgingsstudie som gikk over to år, fant man at fatigue er et vedvarende problem (15). Registrering av depressive symptomer er av interesse. Det er også viktig å undersøke betydningen av andre faktorer enn alder, psykososiale forhold og medikasjon - for eksempel smerte og vitamin D-mangel.

Hovedutfordringen ved fatigue i denne pasientgruppen er, foruten å tilstrebe sykdomsremisjon, de begrensede behandlings- 
alternativene. Selv om løsningsorientert psykoterapi kan ha effekt på kort sikt, og biologisk behandling ser ut til å ha effekt hos en del, savner fortsatt et stort antall pasienter et effektivt behandlingstilbud.

\section{Konklusjon}

Fatigue er et betydelig problem hos pasienter med inflammatorisk tarmsykdom. Aktiv sykdom og depresjon er de faktorene som oftest er assosiert med dette. Det er ønskelig med en standardisert måling av fatigue ved inflammatorisk tarmsykdom.

Økt viten om patofysiologiske mekanismer ved fatigue kan gi grunnlag for nye behandlingsalternativer, noe som er særlig viktig for pasienter med høy grad av fatigue uten aktiv tarminflammasjon.

Vi takker Elisabeth Hundstad Molland ved Fagbiblioteket, Stavanger universitetssjukehus, for oppsett av litteratursøkene til denne artikkelen.

\section{Tore Grimstad (f. 1968)}

er spesialist $\mathrm{i}$ indremedisin og fordøyelsessykdommer, overlege og postdoktor.

Forfatter har fylt ut ICMJE-skjemaet og oppgir følende interessekonflikter: Han har mottatt bidrag fra Abbvie, Tillotts Pharma og Ferring Pharmaceuticals.

\section{Katrine Brække Norheim (f. 1977)}

er lege i spesialisering i indremedisin, konstituert overlege og postdoktor

Forfatter har fylt ut ICMJE-skjemaet og oppgir ingen interessekonflikter.

\section{Litteratur}

1. Baumgart DC, Sandborn WJ. Inflammatory bowel disease: clinical aspects and established and evolving therapies. Lancet 2007; 369: 1641-57.

2. Casati J, Toner BB, de Rooy EC et al. Concerns of patients with inflammatory bowel disease: a review of emerging themes. Dig Dis Sci 2000; 45: $26-31$.

3. Krupp LB, Pollina DA. Mechanisms and management of fatigue in progressive neurological disorders. Curr Opin Neurol 1996; 9: 456-60

4. Norton C, Czuber-Dochan W, Bassett P et al. Assessing fatigue in inflammatory bowel disease: comparison of three fatigue scales. Aliment Pharmacol Ther 2015; 42: 203-11.

5. Flensner G, Landtblom A-M, Söderhamn 0 et al. Work capacity and health-related quality of life among individuals with multiple sclerosis reduced by fatigue: a cross-sectional study. BMC Public Health 2013; 13: 224

6. Dantzer R, O'Connor JC, Freund GG et al. From inflammation to sickness and depression: when the immune system subjugates the brain. Nat Rev Neurosci 2008: 9: 46-56.

7. Norheim KB, Jonsson G, Omdal R. Biological mechanisms of chronic fatigue. Rheumatology (Oxford) 2011; 50: 1009-18.

8. Minderhoud IM, Samsom M, Oldenburg B. Crohn's disease, fatigue, and infliximab: is there a role for cytokines in the pathogenesis of fatigue? World J Gastroenterol 2007; 13: 2089-93.

9. Grimstad T, Norheim KB, Isaksen $\mathrm{K}$ et al. Fatigue in Newly Diagnosed Inflammatory Bowel Disease. Crohn's Colitis 2015: 9: 725-30.

10. Cohen BL, Zoëga H, Shah SA et al. Fatigue is highly associated with poor health-related quality of life, disability and depression in newly-diagnosed patients with inflammatory bowel disease, independent of disease activity. Aliment Pharmacol Ther 2014; 39: 811-22.

11. Goldenberg BA, Graff LA, Clara I et al. Is iron deficiency in the absence of anemia associated with fatigue in inflammatory bowel disease? Am J Gastroenterol 2013: 108: 1392-7.

12. Opheim R, Fagermoen MS, Bernklev T et al. Fatigue interference with daily living among patients with inflammatory bowel disease. Qual Life Res 2014 23: 707-17.

13. van Langenberg DR, Gibson PR. Factors associated with physical and cognitive fatigue in patients with Crohn's disease: a cross-sectional and longitudina study. Inflamm Bowel Dis 2014; 20: 115-25.

14. Yoo S, Jung YS, Park JH et al. Fatigue severity and factors associated with high fatigue levels in Korean patients with inflammatory bowel disease. Gut Liver 2014; 8: 148-53.

15. Graff $L A$, Clara I, Walker JR et al. Changes in fatigue over 2 years are associated with activity of inflammatory bowel disease and psychological factors. Clin Gastroenterol Hepatol 2013; 11: 1140-6.

16. Kappelman MD, Long MD, Martin C et al. Evaluation of the patient-reported outcomes measurement information system in a large cohort of patients with inflammatory bowel diseases. Clin Gastroenterol Hepatol 2014; 12: 1315-23.e2.

17. Bager $\mathrm{P}$, Befrits R, Wikman 0 et al. Fatigue in out-patients with inflammatory bowel disease is common and multifactorial. Aliment Pharmacol Ther 2012; 35: 133-41

18. Tinsley A, Macklin EA, Korzenik JR et al. Validation of the functional assessment of chronic illness therapy-fatigue (FACIT-F) in patients with inflammatory bowel disease. Aliment Pharmacol Ther 2011; 34: 1328-36

19. Graff LA, Vincent N, Walker JR et al. A populationbased study of fatigue and sleep difficulties in inflammatory bowel disease. Inflamm Bowel Dis 2011; 17: 1882-9

20. Römkens TE, van Vugt-van Pinxteren MW, Nagen gast FM et al. High prevalence of fatigue in inflammatory bowel disease: A case control study. J Crohn's Colitis 2011; 5: 332-7.

21. Jelsness-Jørgensen LP, Bernklev T, Henriksen M et al. Chronic fatigue is more prevalent in patients with inflammatory bowel disease than in healthy controls. Inflamm Bowel Dis 2011: 17: 1564-72.

22. Singh S, Blanchard A, Walker JR et al. Common symptoms and stressors among individuals with inflammatory bowel diseases. Clin Gastroenterol Hepatol 2011: 9: 769-75.

23. Lesage $A C$, Hagège $H$, Tucat $G$ et al. Results of a national survey on quality of life in inflammatory bowel diseases. Clin Res Hepatol Gastroenterol 2011: 35: 117-24

24. Romberg-Camps MJ, Bol Y, Dagnelie PC et al. Fatigue and health-related quality of life in inflammatory bowel disease: results from a populationbased study in the Netherlands: the IBD-South Limburg cohort. Inflamm Bowel Dis 2010; 16: 2137-47.

25. Häuser W, Stallmach A, Kocalevent RD et al. Biopsychosocial predictors of fatigue in quiescent and mild ulcerative colitis - an explorative study. Psychosoc Med 2005; 2: Doc07.

26. Minderhoud IM, Oldenburg B, van Dam PS et al. High prevalence of fatigue in quiescent inflammatory bowel disease is not related to adrenocortical insufficiency. Am J Gastroenterol 2003; 98: 1088-93.

27. Casellas F, Barreiro de Acosta M, Iglesias M et al. Mucosal healing restores normal health and quality of life in patients with inflammatory bowel disease. Eur J Gastroenterol Hepatol 2012; 24: 762-9.

28. Banovic I, Gilibert D, Cosnes J. Crohn's disease and fatigue: constancy and co-variations of activity of the disease, depression, anxiety and subjective quality of life. Psychol Health Med 2010; 15: 394-405.

29. Banovic I, Gilibert D, Jebrane A et al. Personality and fatigue perception in a sample of IBD outpatients in remission: a preliminary study. J Crohn's Colitis 2012: 6: 571-7.

30. Christodoulou C. The assesment and measurement of fatigue. I: DeLuca J, red. Fatigue as a window to the brain. Cambridge: The MIT Press 2005: 19-37.

31. Czuber-Dochan W, Norton C, Bassett P et al. Development and psychometric testing of inflammatory bowel disease fatigue (IBD-F) patient self-assessment scale. J Crohn's Colitis 2014; 8: $1398-406$.

32. Smets EM, Garssen B, Bonke B et al. The Multidimensional Fatigue Inventory (MFI) psychometric qualities of an instrument to assess fatigue. J Psychosom Res 1995: 39: 315-25.

33. Beck $A$, Bager $P$, Jensen $P E$ et al. How fatigue is experienced and handled by female outpatients with inflammatory bowel disease. Gastroenterol Res Pract 2013; 2013: 153818

34. Jelsness-Jørgensen LP, Bernklev T, Henriksen M et al. Chronic fatigue is associated with increased disease-related worries and concerns in inflammatory bowel disease. World J Gastroenterol 2012 18: $445-52$

35. Jelsness-Jørgensen LP. Bernklev T, Henriksen M et al. Chronic fatigue is associated with impaired health-related quality of life in inflammatory bowe disease. Aliment Pharmacol Ther 2011; 33: 106-14.

36. Tribbick D. Salzberg M. Ftanou M et al. Prevalence of mental health disorders in inflammatory bowel disease: an Australian outpatient cohort. Clin Exp Gastroenterol 2015; 8: 197-204.

37. Devlen J, Beusterien K, Yen L et al. The burden of inflammatory bowel disease: a patient-reported qualitative analysis and development of a conceptual model. Inflamm Bowel Dis 2014; 20: 545-52.

38. Czuber-Dochan W, Dibley LB, Terry H et al. The experience of fatigue in people with inflammatory bowel disease: an exploratory study. J Adv Nurs 2013. 69: 1987-99.

39. Lichtenstein GR, Bala M, Han C et al. Infliximab improves quality of life in patients with Crohn's disease. Inflamm Bowel Dis 2002; 8: 237-43.

40. Loftus EV, Feagan BG, Colombel JF et al. Effects of adalimumab maintenance therapy on healthrelated quality of life of patients with Crohn's disease: patient-reported outcomes of the CHARM trial. Am J Gastroenterol 2008; 103: 3132-41.

41. Vogelaar L, van't Spijker A, Timman R et al. Fatigue management in patients with IBD: a randomised controlled trial. Gut 2014; 63: 911-8.

42. Wolfe F. Fatigue assessments in rheumatoid arthritis: comparative performance of visual analog scales and longer fatigue questionnaires in 7760 patients. J Rheumatol 2004; 31: 1896-902

43. Smets EM, Garssen B, Bonke B et al. The Multidimensional Fatigue Inventory (MFI) psychometric qualities of an instrument to assess fatigue. J Psychosom Res 1995; 39: 315-25

44. Shergill AK, Lightdale JR, Bruining DH et al. The role of endoscopy in inflammatory bowel disease. Gastrointest Endosc 2015; 81: 1101-21.e1, 13.

45. Walmsley RS, Ayres RC, Pounder RE et al. A simple clinical colitis activity index. Gut 1998; 43: 29-32.

46. Harvey RF, Bradshaw JM. A simple index of Crohn's-disease activity. Lancet 1980; 1: 514.

47. Jelsness-Jørgensen LP. Bernklev T, Moum B. Fatigue and disease-related worries among inflammatory bowel disease patients in remission is it a reflection of coexisting IBS-like symptoms? A short report J Psychosom Res 2012: 73: 469-72.

48. Diagnostic and Statistical Manual of Mental Disorders, Fifth edition (DSM-V). Washington, D.C. American Psychiatric Association, 2013.

Mottatt 12.2. 2016, første revisjon innsendt 30.5 2016, godkjent 24.8. 2016. Redaktør: Ragnhild Ørstavik. 